\title{
Monitoring Carbon Dioxide and Methane Levels above Retired Landfill and Forest Control Sites with a Tethered Aerostat to Determine Remediation Effectiveness
}

\author{
Jesse Banick, Kathryn Lenz, Jonathan Sanders, Jeshanah Zolkowski ${ }^{1}$ \\ University of Wisconsin-Fox Valley, Menasha
}

\begin{abstract}
The chemical composition of the ambient air not only affects the health of human beings, but also the health of the planet. This study examined how the decay of waste matter influenced the concentration of carbon dioxide and methane in ambient air. By measuring the level of these two gases above a forest control site and a retired landfill site, the researchers analyzed the effectiveness of the remediation methods utilized on the retired landfill in reducing carbon dioxide and methane emissions. Two carbon dioxide sensors, affixed to a payload, hung beneath a tethered aerostat. The collected data seemed to show that the concentration of carbon dioxide on the retired landfill was equal to the concentration at the control site. However, as the data may have been influenced by sensor limitations, more analysis needs to be done to make conclusions about the remediation effectiveness.
\end{abstract}

\section{Introduction and Literature Review}

Landfills, carbon dioxide, and methane. Each load of refuse added to a landfill provides a meal for microorganisms living inside. As these organisms perform their metabolic processes, they release a variety of gases, comprised mainly of carbon dioxide and methane (EPA, 2000). These emissions continue even after the landfill has been covered and seeded. Waste management companies have utilized multiple capping methods to reduce these gaseous emanations. For example, if the method involves a vegetative layer, the aeration of the soil is increased greatly. This allows oxygen to diffuse more readily into the soil (Abichou, Kormi, Yuan, Johnson, \& Francisco, 2015). If toxins such as methane are oxygenated, they are not as detrimental to the environment.

While including vegetation in landfill capping proves to be important in itself, the type of vegetation also matters. Depending on the climate, soil constituents, and overall ecology of the area, different plant species will prosper and multiply. Healthier plants tend to photosynthesize more, having more leaves and chloroplasts. This increased rate of photosynthesis allows the plant to capture carbon dioxide and build sugars faster. Although the impact of plant species on atmospheric carbon dioxide is cited more often in literature, their impact on methane concentration is not as well known. Methanotrophs, small organisms that intake methane as an energy source, thrive in the soil of landfills with dense foliage. According to Stralis-Pavese and her colleagues (2004), the abundance of these bacteria depends on the plant species present. Finding the optimal environment for methane consumption by methanotrophs will help curb the amount of methane in the ambient air. Understanding the role of landfill capping and seeding in gas emissions has been a small chapter in the history of atmospheric research.

\footnotetext{
${ }^{1}$ This research was made possible by Wisconsin Space Grant Consortium, Dr. Beth A. Johnson, Dave's Sport and Marine in Kaukauna, City of Kaukauna, High Cliff State Park, Weld Specialty in Kaukauna, Dan Hawk, other UW Fox Valley Faculty (Dr. Brian Rukamp, Joy Perry, Dr. Martin Rudd), and our Affiliate Student Interns (Leigh Hayes, Katie Stadler, William Talbot, Zach Dorn, Erika Petersen, Cassondra Parsons).
} 
History of carbon dioxide and methane monitoring. Interest in the concentration of greenhouse gases has prompted scientific research for over 50 years. Consistent monitoring of carbon dioxide levels began in the mid-1900s with Charles David Keeling. Keeling used infrared sensor techniques to read the carbon dioxide concentration at Mauna Loa Observatory in Hawaii, discovering pertinent trends. The concentration of carbon dioxide across the globe rose steadily (Roston, 2008).Teachers, authors, and businesses have dedicated classes, books, and products to the prevention of this trend. They focus on the role of human beings in the rise of carbon dioxide. Burning fossil fuels to power vehicles, furnaces, and industrial machines emit these gases into the atmosphere.

Monitoring of another small molecule, methane, has a more recent history. Scientists started to track its atmospheric concentration about 20 years after carbon dioxide. Although it traps more heat in the Earth's atmosphere than carbon dioxide, its concentration is minute in comparison (Roston, 2008). Along with the aforementioned landfill-related production of methane, oil companies also unearth the gas while drilling (Climate Central, 2012). Although carbon dioxide and methane are microscopic, they can cause problems that are macroscopic.

Greenhouse gases and climate change. The most cited and far-reaching consequence of higher levels of carbon dioxide and methane in the atmosphere is the greenhouse effect, which causes climate change. The emissions of carbon dioxide that originate from landfills are low at only $0.1 \%$ of total carbon dioxide emissions (Carbon Dioxide Emissions by Sector, 2015). However, landfill emissions of methane contribute $18 \%$ of its total emissions (U.S. Methane Emissions by Source, 2013). With the Environmental Protection Agency (EPA) reporting about 3,500 landfills in the United States as of 2012, improving bioremediation at landfills could help curb the concentration of these gases in Earth's atmosphere (U.S. Environmental Protection Agency, 2012). The concentration of these two gases in the atmosphere causes climate change by blocking portions of the sun's radiation from exiting the Earth's atmosphere, causing the radiation to reflect back to the ground and warm the overall temperature of Earth (Climate Central, 2012). The rise of greenhouse gases is expected to contribute to various effects that could be detrimental to the Earth's health. The increased temperatures caused by climate change may lead to an escalation of heat stroke and other heat related illnesses. Climate change will also impact Earth's ecology by causing more forest fires. Forest fires are especially dangerous since they will result in a lack of trees to remove carbon dioxide from the atmosphere, compounding the initial problem (Greenhouse Gases, 2015). Another hypothesis is that climate change will not increase temperatures evenly across Earth, but only in certain parts. This would alter normal precipitation and evaporation patterns, causing natural plant communities to shift along with precipitation trends (Climate Change Causes, 2015). Another impact of climate change is glacial formations melting. 
This would cause a rise in the ocean's water level, displacing communities that live under sea level, as well as saltwater getting into the water table (Greenhouse Gases, 2015).

\section{Methods}

Ascent of the tethered aerostat. The tethered aerostat, a Lighter Than Air Systems (LTAS) Kingfisher Aerostat K7.5U, held $230 \mathrm{cf}$ of helium. The 7-lb lift capacity dictated the amount of equipment allowed on the payload. The planned concept of operations, locking the winch for five minutes at $50 \mathrm{~m}, 70 \mathrm{~m}$, and $90 \mathrm{~m}$ above ground level, was followed as closely as possible. The five minute lapses were meant to give the sensors time to adjust to the new elevation and gain an accurate reading of the gas concentration at that altitude. However, the wind caused unexpected altitude variations during the lapse periods. These fluctuations did not allow the sensors to remain suspended at the planned elevations.

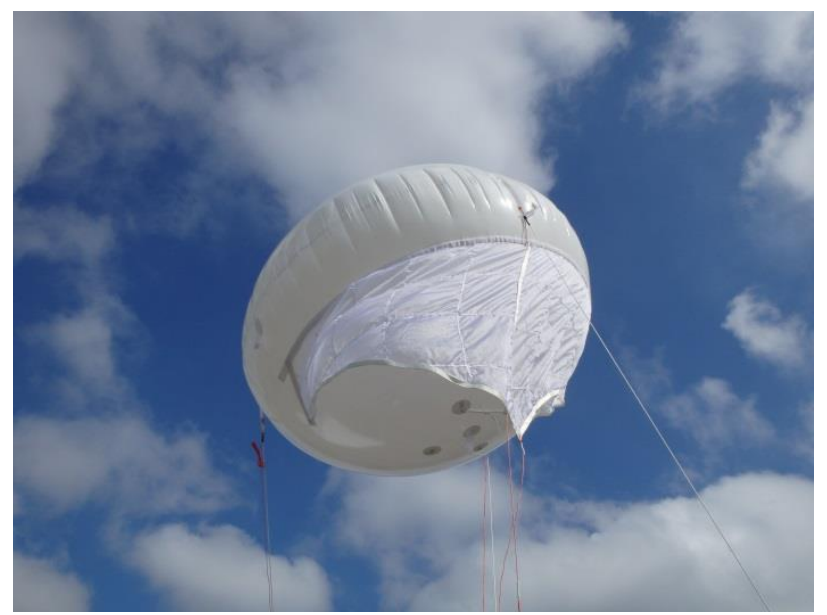

Figure 1. The aerostat is shown below; the payload was suspended by ropes below the balloon. Photo by Beth Johnson

Measurement of gas concentrations, GPS, and altitude data. Three sensors took readings while attached to the ascending payload. The MG-811 carbon dioxide sensor worked as a galvanic cell to produce output voltages corresponding to the concentration of carbon dioxide in the air around it ("MG811 CO2 Sensor," n.d.). The range at which this device senses is 350-10,000ppm. The other carbon dioxide sensor, the K-30 sensor, gained readings with non-dispersive infrared waveguide methods (Datasheet: K-30 Sensor," 2015). Having a range of 0-2000ppm, this sensor proved to be more fine-tuned since its range spanned the expected results evenly and completely. Although the sensitivity of $1 \%( \pm 20 \mathrm{ppm})$ and accuracy of $3 \%( \pm 30 \mathrm{ppm})$ is large in this application, the uncertainty would be lessened greatly by calculating an uncertainty in the mean concentration at each site, provided with a large collection of sensor readings. The last sensor, the MQ-4 methane sensor, was present on the payload but did not produce 
reliable data and was not included in this report (Hanwei Electronics, n.d.). The voltage output from the output pins on each sensor travelled through a wire and resistor pack to the positive input pins on the GPS Aim XTRA (GAX). The GAX sent this voltage data, along with altitude and GPS data, to the AIM Base receiver attached to a ground computer. This data saved on the computer through the GAX software.

Power supply and payload board. An 11.4V 2200mAH LiPo battery powered the GPS Aim XTRA, while the sensors ran off of a $7.4 \mathrm{~V}, 2200 \mathrm{mAh}$ battery. A teardrop-shaped piece of birch, artist-grade plywood provided support for research equipment. This plywood hung from the aerostat by three ropes attached to a swivel tethered to the aerostat. A metal tail steadied the payload in the wind.

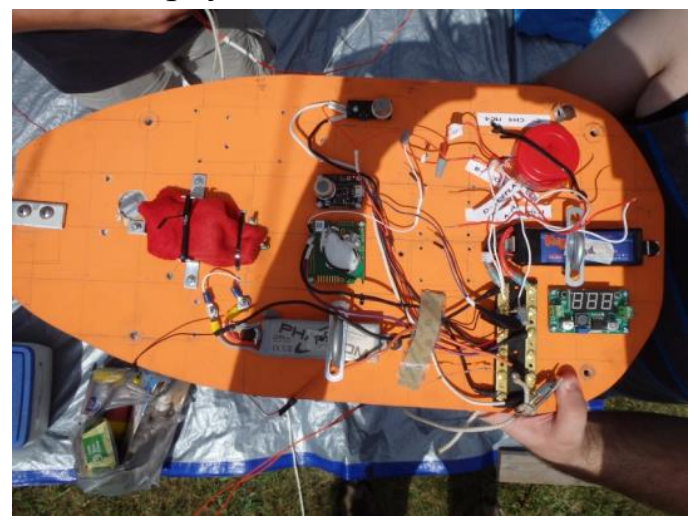

Figure 2. Batteries, sensors, a camera, the GPS Aim XTRA, and other equipment were mounted on the board. Photo by Beth Johnson

Location of retired landfill and control site. The retired landfill this study analyzed was the former Lehrer Landfill located in Kaukauna, Wisconsin. The aerostat ascended at latitude $44.261777^{\circ} \mathrm{N}$ longitude $88.267557^{\circ} \mathrm{W}$. After collecting data at this location, the aerostat was transported to High Cliff State Park. The launch site in the park was near Indian Mound Trail, latitude $44.155251^{\circ} \mathrm{N}$ longitude $88.296176^{\circ} \mathrm{W}$.

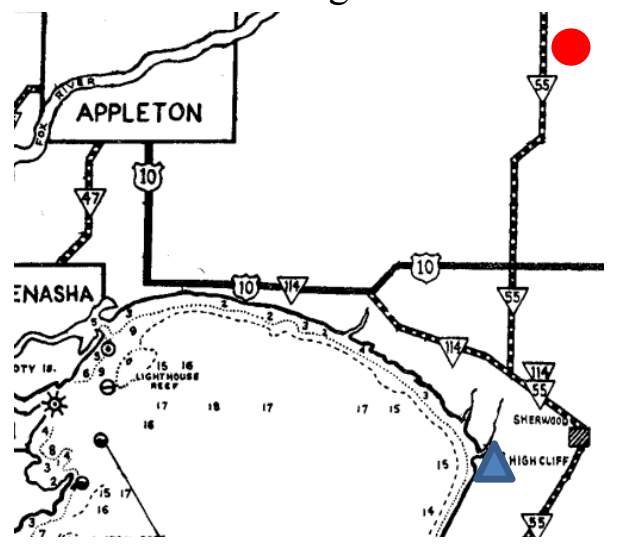

Figure 3. Map of the approximate locations of Lehrer Landfill (red circle) and High Cliff State Park (blue triangle) in Northeast Wisconsin.

Source: Wisconsin Department of Natural Resources 


\section{Data and Observations}

The first sets of data presented are Graphs $1 \mathrm{a}$ and $1 \mathrm{~b}$, representations of the data collected from Lehrer Landfill with the MG-811 carbon dioxide sensor. Graph 1a plots carbon dioxide concentration versus the amount of time the sensor was functioning. In Graph $1 \mathrm{~b}$, the concentration of carbon dioxide is plotted versus the altitude the aerostat achieved during the launch. Graphs $2 \mathrm{a}$ and $2 \mathrm{~b}$ follow, which are representations of the data collected from High Cliff State Park with the MG-811 carbon dioxide sensor. Graphs 3a and $3 \mathrm{~b}$ also represent data from High Cliff State Park, but from the K-30 carbon dioxide sensor. Graphs $2 \mathrm{a}, 2 \mathrm{~b}, 3 \mathrm{a}$, and $3 \mathrm{~b}$ are of the same format as graphs $1 \mathrm{a}$ and $1 \mathrm{~b}$. Power supply issues were experienced at both sites, and are responsible for many of the otherwise inexplicable fluctuations seen in the graphs. Since the voltage-concentration conversion was unknown, the concentration in parts per million (ppm) were calculated by assuming High Cliff State Park (the control) had approximately 400 ppm (the average $\mathrm{CO}_{2}$ concentration of clean air). The data was collected as an analog voltage from both sensors, which was averaged. That average was then assumed to be approximately 400 ppm, which allowed the creation of a conversion factor for ppm per volt. In addition, the altitude values from the GPS Aim XTRA did not match observed heights. Battery troubles may have caused this discrepancy. This problem became apparent at High Cliff State Park; as a result, the altitude values on these graphs were approximated. While the payload rose, the gas concentration data seemed unrelated to altitude deviations. Therefore, the altitude correction does not have a large bearing on the research results.

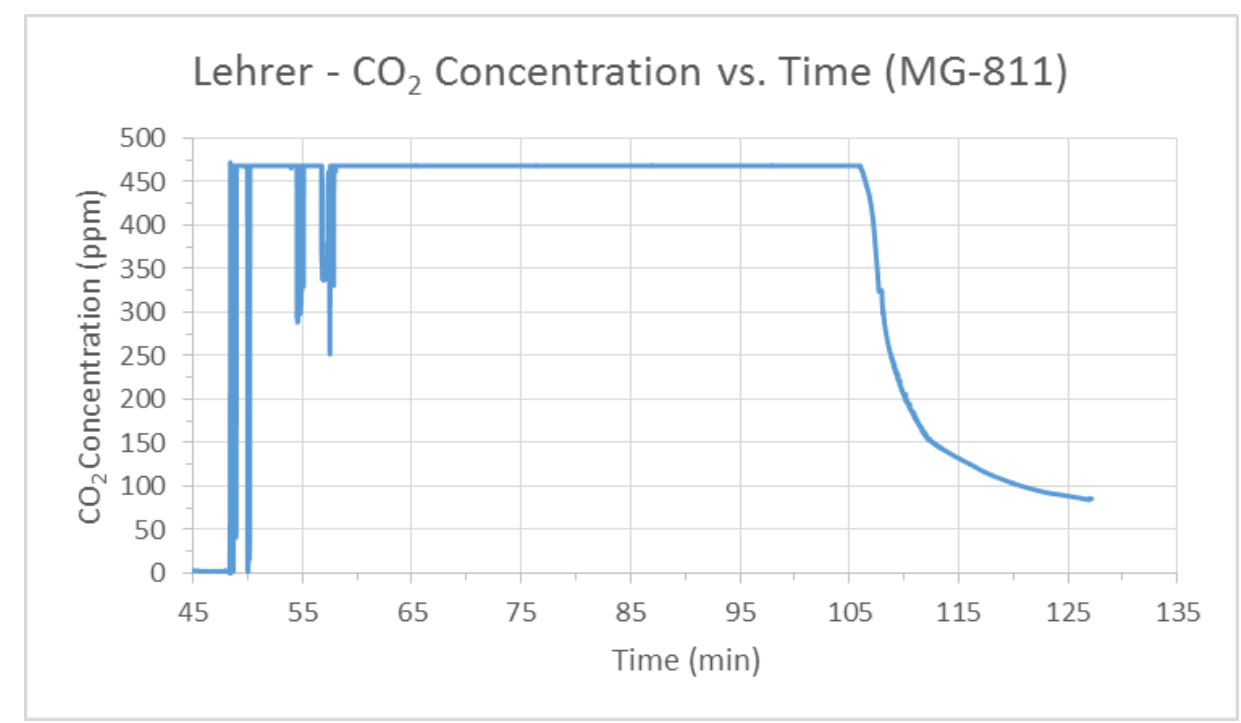

Graph 1a: A graph of $\mathrm{CO}_{2}$ concentration versus time of the MG-811 at Lehrer Landfill. Time is on the $\mathrm{x}$-axis from 45-135 min. $\mathrm{CO}_{2}$ Concentration from the MG-811 carbon dioxide sensor is on the y-axis from 0-500 ppm. The time before 45 minutes was omitted due to a connection or battery failure that resulted in a reading of zero. When the graph decreases rapidly at the end, this is due to the battery failing and supplying less power to the sensor. 


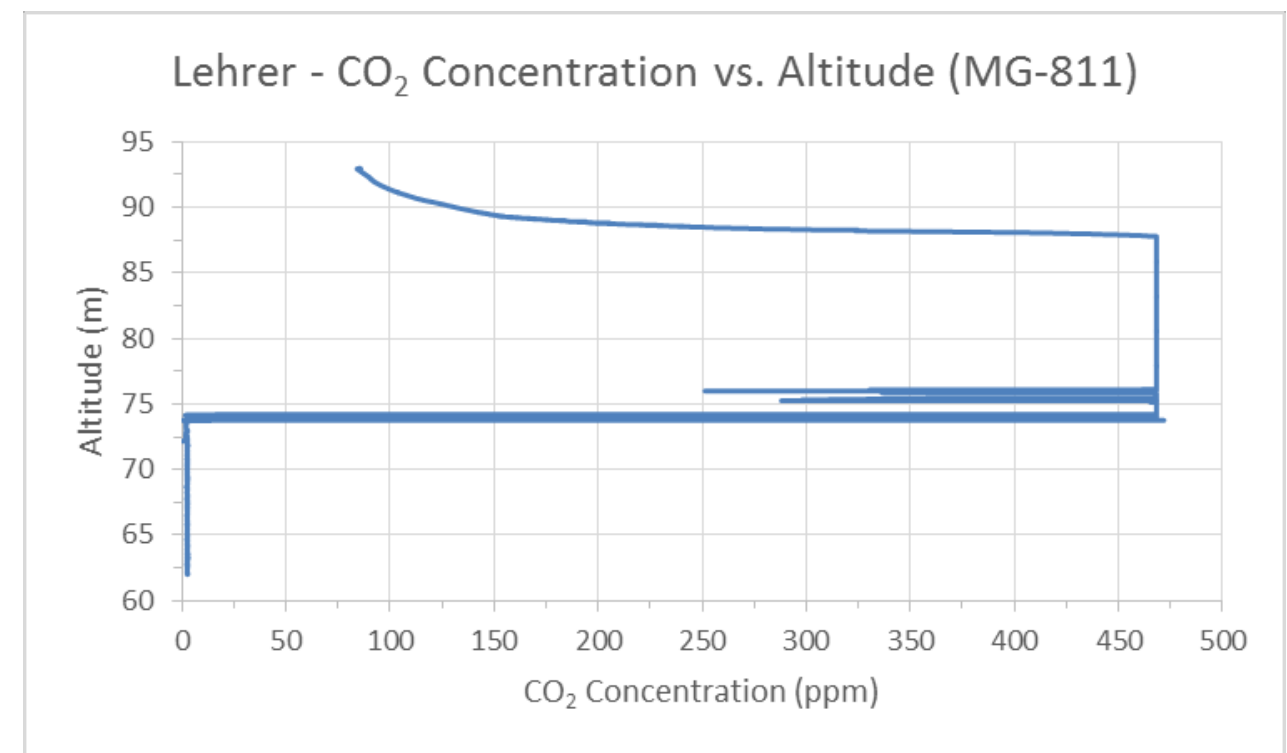

Graph 1b: A graph of $\mathrm{CO}_{2}$ concentration versus altitude of the MG-811 at Lehrer Landfill. Altitude is on the y-axis from $60-95 \mathrm{~m} . \mathrm{CO}_{2}$ concentration from the MG-811 carbon dioxide sensor is on the $\mathrm{x}$-axis from $0-500 \mathrm{ppm}$. The altitude before $60 \mathrm{~m}$ was omitted because there were no data points. The altitude is above sea level, and we launched from over 50m above sea level. Unexpected drops in $\mathrm{CO}_{2}$ concentration are believed to be due to battery failure.

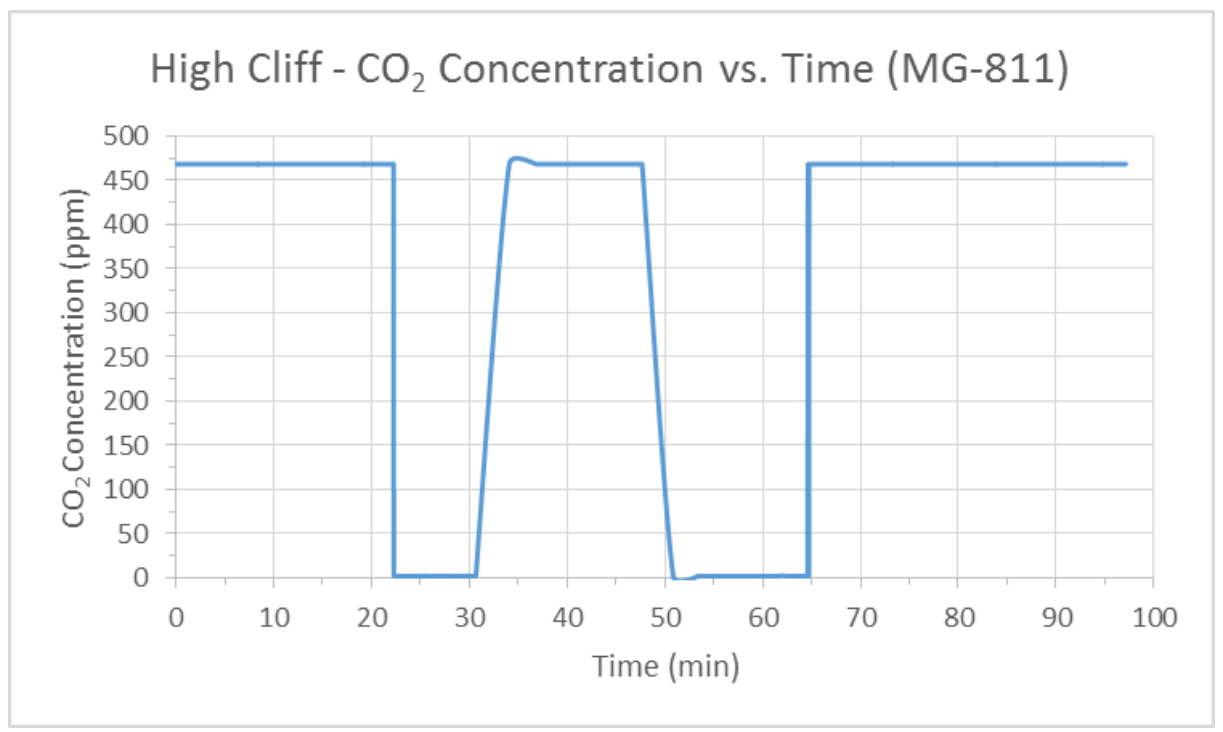

Graph 2a: A graph of $\mathrm{CO}_{2}$ concentration versus time of the MG-811 at High Cliff State Park. Time is on the $\mathrm{x}$-axis from 0-100 min. $\mathrm{CO}_{2}$ concentration of the MG-811 carbon dioxide sensor is on the y-axis from 0-500 ppm. The times where the $\mathrm{CO}_{2}$ concentration reaches zero is believed to be due to battery failure, which resulted in the sensor being unable to read the concentration of carbon dioxide. 


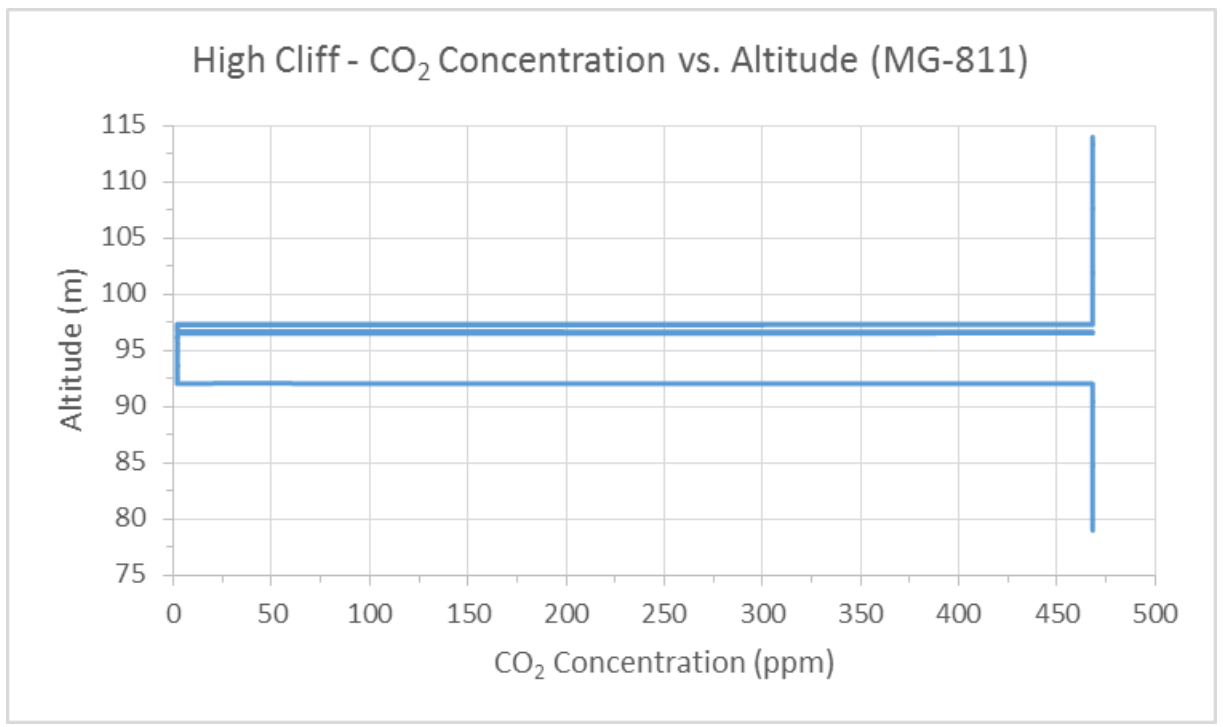

Graph 2b: A graph of $\mathrm{CO}_{2}$ concentration versus altitude of the MG-811 at High Cliff State Park. Altitude is on the yaxis from 75-115 m. $\mathrm{CO}_{2}$ concentration of the MG-811 carbon dioxide sensor is on the $\mathrm{x}$-axis is from 0-500 ppm. The altitude before $75 \mathrm{~m}$ was omitted because there were no data points. The altitude is above sea level, and the platform was launched from over $50 \mathrm{~m}$ above sea level. The $\mathrm{CO}_{2}$ concentration reaching $0 \mathrm{ppm}$ is believed to be due to battery failure.

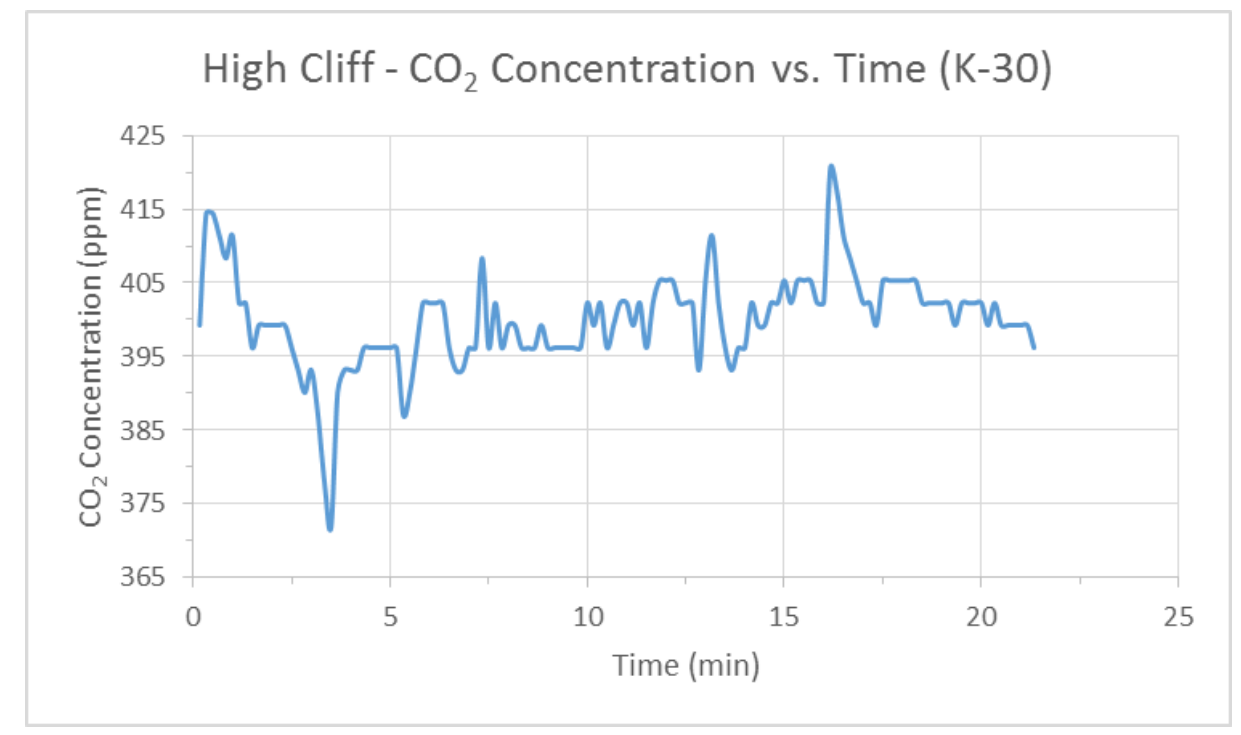

Graph 3a: A graph of $\mathrm{CO}_{2}$ concentration versus time of the K-30 carbon dioxide sensor at High Cliff State Park. The sensor was within its error margin, and the fluctuations show that the sensor was not simply reading a preset "maximum" or "minimum" voltage. The peaks may be a result of changing wind velocities. Therefore, the sensor responds to its environment. 


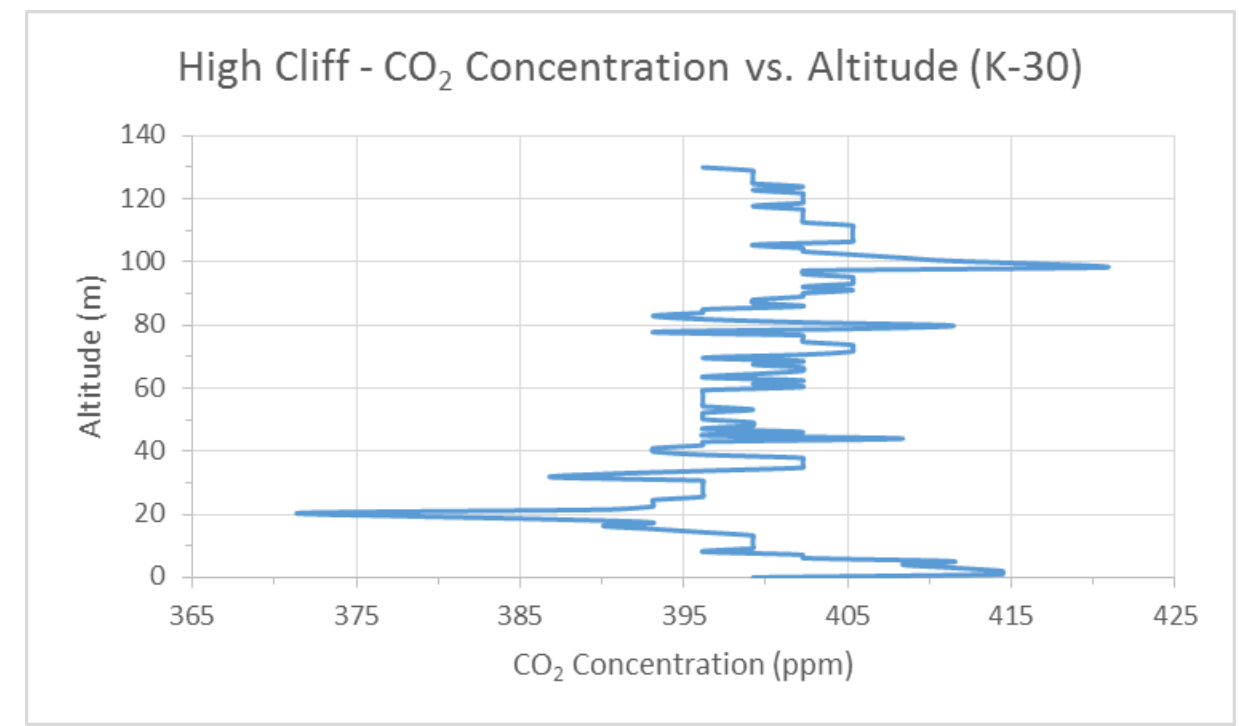

Graph 3b: A graph of $\mathrm{CO}_{2}$ concentration versus altitude of the K-30 at High Cliff State Park. Please refer to the explanation of Graph 3a for an analysis of data peaks and depressions.

\section{Discussion}

Although the data appears to illustrate equal concentrations of carbon dioxide at the retired landfill and control site, more testing is required in order to deem this information reliable. The voltage corresponding to the highest concentration on the MG-811 is about $3.3 \mathrm{~V}$, which may have simply been the maximum voltage on the sensor. Therefore, the unchanging graph concentrations may not be accurate. As can be seen on the graph from the MG-811 sensor, there are two drastic drop offs where the voltage falls to $0 \mathrm{~V}$. This is a result of a loose connection between the sensor and either the power supply or the GAX, and not a result of a drop in ppm detected.

The drops that are seen on graph $1 \mathrm{~b}$ are not the only complications that arose from the power supply. The GAX coordinates that came from the control site are also skewed due to a lack of power. Being that the real time data was viewed on the ground computer unit while the aerostat was afloat, it became apparent that the GAX was providing false elevation coordinates. Once the aerostat had landed, a simple voltage test revealed that the battery supplying energy to the GAX was no longer charged. This has no detrimental effect on the data, because both of the sensors remain consistent at all elevations throughout the second launch at the control site. 


\section{Conclusion}

After launching at Lehrer Landfill and High Cliff, permission to launch at Outagamie County Landfill in Little Chute, WI was granted. Outagamie County Landfill is an active landfill and will enable the completion of the bioremediation analysis. Once the active landfill's data is obtained, a comparison between the data from the control and retired sites will be made. This will show how effective the remediation methods where in returning the concentrations of carbon dioxide to the ambient air's original concentration at the control.

Another part of research will be testing for heavy metal ions in the groundwater that surrounds the test sites. The purpose of this test is to see if there are any other heavy metals prevalent at landfill versus control. This will also tell whether the plants at the retired landfill are having any effect on the other heavy metals present.

To further ascertain the relationship between the landfill and its vegetation, analysis of pictures taken from above the launch site by the ADC Micro will be done in the coming months. With this camera, pictures can be filtered such that the percentage of healthy plants in a given area will be apparent. This will be correlated with how effective the bioremediation is. The plan is to identify the species of plants on these sites to see if any plants in particular are helpful in removing carbon dioxide and methane.

A major flaw in this launch was a lack of correspondence with the MG-81 sensor. The MG-811 sensor does not have a clear voltage associated with a certain concentration of carbon dioxide. An experiment containing bromothymol blue along with $\mathrm{CO}_{2}$ will be conducted in a controlled environment to make sure that the MG-811 sensor is reading at an increasing rate in accordance with the bromothymol blue. More research will be done to reveal a voltage to ppm correspondence for this particular sensor.

The ultimate goal of this research is to determine if planting vegetation on inactive landfills helps counter the emission of carbon dioxide and methane. This research also examines the effects of vegetation on the presence of heavy metal ions. In order to determine this, it is necessary to analyze the concentrations of carbon dioxide and methane in the atmosphere, as well as analyzing heavy metal ions in groundwater nearby. In addition, landfills with various types of vegetation will be compared discover the optimal planting method for improving environmental sustainability at landfill sites. 


\section{References}

Abichou, T., Kormi, T., Yuan, L., Johnson, T., \& Francisco, E. (2015). Modeling the effects of vegetation on methane oxidation and emissions through soil landfill final covers across different climates. Waste Management, 36230-240. doi:10.1016/j.wasman.2014.11.002

Carbon Dioxide. (2013, August 7). Retrieved September 15, 2015, from Wisconsin Department of Health Services website: https://www.dhs.wisconsin.gov/chemical/carbondioxide.htm

Carbon Dioxide Emissions by Sector, 2013 (Excluding LULUCF) [Image]. (2015, July 2). Retrieved from https://www.gov.uk/government/uploads/system/uploads/attachment_data/file/441367/Carbon_Dioxide_20 13_Issue1.1.pdf

Climate Change Causes: A Blanket around the Earth. (n.d.). Retrieved September 15, 2015, from Climate Change: Vital Signs of the Planet website: http://climate.nasa.gov/causes/

Climate Central. (2012). Global Weirdness: Severe Storms, Deadly Heat Waves, Relentless Drought, Rising Seas, and the Weather of the Future. New York, NY: Pantheon Books.

Datasheet: K-30 Sensor [Fact sheet]. (2015, May). Retrieved September 7, 2015, from http://co2meters.com/Documentation/Datasheets/DS30-01\%20-\%20K30.pdf

Greenhouse Gases Pose Threat to Public Health. (n.d.). Retrieved September 15, 2015, from News website: http://www.hsph.harvard.edu/news/features/bernstein-greenhouse-gases-health-threat/

Hanwei Electronics. (n.d.). Technical Data MQ-4 Gas Sensor [Fact sheet]. Retrieved September 7, 2015, from http://www.sainsmart.com/zen/documents/20-011-957/MQ-4.pdf

Methane: Health Effects and Incident Management. (n.d.). Retrieved September 15, 2015, from: https://www.gov.uk/government/publications/methane-properties-uses-and-incident-management

MG811 CO2 Sensor [Fact sheet]. (n.d.). Retrieved September 7, 2015, from http://www.dfrobot.com/image/data/SEN0159/CO2b\%20MG811\%20datasheet.pdf

Roston, E. (2008). The Carbon Age: How Life's Core Element Has Become Civilization's Greatest Threat. New York, NY: Walker.

Stralis-Pavese, N., Sessitsch, A., Wellharter, A., Reichenauer, T., Riesing, J., Csontos, J., \& ... Bodrossy, L. (2004). Optimization of diagnostic microarray for application in analysing landfill methanotroph communities under different plant covers. Environmental Microbiology, 6(4), 347-363. doi:10.1111/j.1462-2920.2004.00582.x

U.S. Environmental Protection Agency List of Municipal Solid Waste Landfills [Image]. (2012, April 2). Retrieved from http://www3.epa.gov/epawaste/nonhaz/municipal/landfill/section3.pdf

U.S. Methane Emissions, By Source [Image]. (2013, May 9). Retrieved from http://www3.epa.gov/climatechange/ghgemissions/gases/ch4.html

Wolfe, L. (n.d.). Winnebago Lake [Map]. Wisconsin Department of Natural Resources. Retrieved from http://dnr.wi.gov/lakes/maps/DNR/0139900a.pdf 